\title{
HUBUNGAN PENANGANAN AWAL GASTRITIS DENGAN SKALA NYERI PASIEN UGD RUMAH SAKIT GMIM BETHESDA TOMOHON
}

\author{
Irfan Irianto Rizky \\ Billy J. Kepel \\ Maykel Killing \\ Program Studi Ilmu Keperawatan Fakultas Kedokteran \\ Universitas Sam Ratulngi \\ Email : Irfanrizky22@Gmail.Com
}

\begin{abstract}
Gastritis is inflammation of the gastric mucosa and sub gastric mucosa. the management of gastritis which needs to be considered as the main problem or the patient's main consideration of this disease is pain. The initial management of gastritis can affect the patient's pain intensity. The purpose of the study was to identify the relationship between the initial management of gastritis and the patient's pain scale at UGD RSU GMIM Bethesda tomohon. Method uses a correlation analytic research design with a cross sectional approach The sample in this study patients who entered the Emergency Room of the GMIM Hospital in Bethesda Tomohon and had been gastritis diagnosed with a population is 60 patients. Results of the study used the spearmen's test at a significance level is 95\%, significant for initial management of gastritis with the patient's pain scale ( $p$ value 0,$066 ; \alpha 0,05)$. Conclusion, initial management of gastritis related with the patient's pain scale at UGD RSU GMIM Bethesda Tomohon.
\end{abstract}

Keywords : Gastritis, initial Management of Gastritis, Pain Scale.

\begin{abstract}
Abstrak : Gastritis adalah proses inflamasi pada mukosa lambung dan sub mukosa lambung. Dalam penatalaksanaan penyakit gastritis hal yang perlu diperhatikan yang menjadi masalah atau keluhan utama pasien dari penyakit ini adalah nyeri. Penatalaksanaan awal gastritis dapat mempengaruhi insensitas nyeri pasien. Tujuan penelitian untuk mengindentifikasi hubungan antara penatalaksanaan awal gastritis dengan skala nyeri pasien UGD RSU GMIM Bethesda Tomohon. Metode penelitian ini menggunakan desain penelitian analitik korelasi dengan pendekatan cross sectional. Sampel penelitian ini adalah pasien yang masuk di UGD RSU GMIM Bethesda Tomohon dan telah didiagnosis gastritis dengan jumlah populasi sebanyak 60 pasien. Hasil penelitian dengan menggunakan uji spearman pada tingkat kemaknaan 95\%, signifikan untuk penatalaksanaan awal gastritis dengan skala nyeri pada pasien (nilai p 0,066 ; $\alpha$ 0,05). Kesimpulan, Penatalaksanaan awal gastritis berhubungan secara bermakna dengan skala nyeri pasien gastritis di UGD RSU GMIM Bethesda Tomohon.
\end{abstract}

Kata Kunci : Gastritis, Penatalaksanaan awal Gastritis, Skala Nyeri 


\section{PENDAHULUAN}

Gastritis adalah proses inflamasi pada mukosa lambung dan sub mukosa lambung. Gastritis merupakan gangguan kesehatan yang paling sering dijumpai di klinik diagnosisnya sering hanya berdasarkan gejala klinis bukan pemeriksaan hispatologi (Priyanta, 2008). Menurut penjelasan Price \& Wilson (2006) Gastritis merupakan suatu keadaan peradangan atau perdarahan mukosa lambung yang dapat bersifat akut, kronis, difus, atau lokal. Gastritis atau "maag" atau sakit ulu hati adalah peradangan pada dinding lambung. Gastritis merupakan gangguan yang paling sering ditemui dalam praktek sehari-hari karena diagnosis penyakit ini hanya berdasarkan gejala klinis. Penyakit ini sering dijumpai timbul secara mendadak yang biasanya ditandai dengan rasa mual atau muntah, nyeri, pendarahan, rasa lemah, nafsu makan menurun atau sakit kepala (Anggita, 2012)

Gastritis disebabkan oleh infeksi kuman Helicobacter pylori dan pada awal infeksi mukosa lambung menunjukkan respons inflamasi akut dan jika diabaikan akan menjadi kronik (Sudoyo $d k k$. 2009). Penyebab gastritis dibedakan atas faktor internal yaitu adanya kondisi yang memicu pengeluaran asam lambung yang berlebihan dan faktor eksternal yang menyebabkan iritasi dan infeksi (Fatmaningrum, $d k k$. 2009). Beberapa penyebab kejadian gastritis adalah menggunakan obat aspirin atau antiradang non steroid, infeksi kuman Helicobacter pylori, kebiasaan minumminuman beralkohol, memiliki kebiasaan merokok, sering mengalami stress dan kebiasaan minum kopi (Maulidiyah, 2006).

Kejadian gastritis didunia dialami oleh penduduk berjumlah 1,8-2,1 juta dari jumlah penduduk setiap tahunnya. Sedangkan kejadian gastriris diberbagai dunia yang lain seperti halnya di Inggris sekitar $22 \%$ dari jumlah penduduk, Cina sekitar 31\%, Jepang sekitar 14,5\%, Kanada sekitar 35\% dan Perancis sekitar 29.5\%. Di Asia Tenggara persentase kejadian gastritis tergolong besar, jumlah total penduduk yang mengalami penyakit gastritis berjumlah 583.635 jiwa dari jumlah penduduk dalam setiap tahunnya. Presentase dari angka kejadian gastritis di Indonesia menurut World Health Organization (WHO) adalah 40,8\%. Persentase dari angka kejadian gastritis di Indonesia menurut WHO didapatkan mencapai angka 40,8\%. Berdasarkan profil kesehatan Indonesia tahun 2010, gastritis merupakan peringkat ke lima dari 10 besar penyakit terbanyak pasien rawat inap yaitu 24,716 kasus dan peringkat ke enam dari 10 besar penyakit terbanyak rawat jalan di Rumah Sakit di Indonesia yaitu 88,599 kasus. Angka kejadian gastritis pada beberapa daerah di Indonesia cukup tinggi dengan prevalensi 274,396 kasus dari 238,452,952 jiwa penduduk. Berdasarkan hasil penelitian dan pengamatan yang dilakukan oleh Departemen Kesehatan RI dan angka kejadian gastritis tertinggi mencapai $91,6 \%$ yaitu di kota Medan. Berdasarkan data dari Dinas Kesehatan Propinsi Sumatera Barat tahun 2013 dan data tahun 2014 menurut urutan 10 besar penyakit terbanyak di Sumatera Barat gastritis menempati urutan ke 2 (dua) dengan jumlah penderita sebesar 202.138 kasus (Depkes RI, 2014).

Menurut amin dalam tujuan dari penanganan awal medis untuk memenuhi kebutuhan yang paling penting dahulu kemudian meningkatkan yang tidak terlalu penting. Adapun hirarki kebutuhan tersebut adalah kebutuhan fisiologis dasar, kebutuhan akan rasa aman dan tentram, kebutuhan akan dicintai dan disayangi, kebutuhan untuk dihargai, dan kebutuhan untuk aktualisasi diri. Kebutuhan fisiologis adalah pertahanan hidup jangka pendek. Kebutuhan fisiologis ini sangat kuat, dalam keadaan absolute (kelaparan dan kehausan) semua kebutuhan lain ditinggalkan dan mencurahkan semua kemampuannya untuk memenuhi kebutuhan ini (Amin,2017).

Data dari medical record RSU GMIM Bethesda Tomohon pada bulan oktober 2018 terdapat 120 orang dengan diagnosis gastritis yang masuk di UGD. Pasien rata- 
rata datang dengan keluhan Nyeri, pasien mendapatkan pengkajian terhadap penyakitnya dan pasien tersebut mendapatkan pengananan awal gastritis yaitu berupa tindakan farmakologis dan nonfarmakologis ketika pasien tersebut tiba di UGD, namun kejadian di lapangan setelah diberikan penatalaksanaan awal gastritis terdapat beberapa pasien yang menyatakan bahwa nyeri yang dirasakan tidak kunjung hilang, bisa dikatakan tujuan dari penatalaksanaan gawat darurat yang dilakukan belum tercapai.

\section{METODE PENELITIAN}

Desain penelitian yang di gunakan yaitu studi korelasi dengan pendekatan cross sectional yaitu studi epidemiologi yang mengukur beberapa variabel dalam satu saat sekaligus. Dengan populasi pada penelitian ini yaitu pasien gastritis yang berjumlah 60 responden yang di peroleh dari observasi diruangan UGD RSU GMIM Bethesda Tomohon selama 2 minggu dengan Sampel yang diperoleh yang telah memenuhi kriteria inklusi berjumlah 52 responden untuk pasien gastritis yang diperoleh dari data rumah sakit umum GMIM Bethesda Tomohon, menggunakan teknik non random sampling dan di hitung menggunakan rumus slovin, berikut cara perhitungannya.

Instrument yang digunakan dalam variabel penanganan awal gastritis, pengumpulan data menggunakan alat ukur kuesioner yang telah baku dan tervalidasi, dengan hasil perhitungan skala koefisien reprodusibilitas sebesar 0,98 dan skala koefisien skalabilitas sebesar 0,97. Pada kuesioner ini terdiri dari 10 pertanyaan yang terdiri dari 2 point jawaban yaitu $(y a)$ dan (tidak), dan masing-masing jawaban memiliki skor yaitu 1 untuk jawaban (ya) dan 0 untuk jawaban (tidak). Dari hasil penilaian kuesioner tersebut terdapat 3 hasil kriteria yaitu, baik : apabila nilai skor 8-10, cukup : apabila nilai skor 4-7, dan kurang : apabila nilai skor 0-3. Pemberian instrument penelitian terhadap di berikan setelah pasien telah mendapatkan penatalaksanaan awal yang berlangsung sekitar < 1 jam setelah di berikan penatalaksanaan awal. Sedangkan pada variabel skala nyeri instrument yang digunakan dalam pengumpulan data yaitu NRS (numeric rating scale) dimana instrumen tersebut merupakan metode pengkajian skala nyeri pada pasien yang telah baku dan menjadi patokan dalam mengkaji skala nyeri pasien. Instrumen ini terdiri 10 tingkatan nyeri dengan 3 kriteria hasil yaitu skor 1-3 untuk skala nyeri ringan, skor 4-6 untuk skala nyeri sedang dan 7-10 untuk skala nyeri berat. Pemberian instrument penelitian terhadap di berikan setelah pasien telah mendapatkan penatalaksanaan awal yang berlangsung sekitar < 1 jam setelah di berikan penatalaksanaan awal.

\section{HASIL dan PEMBAHASAN}

\section{A. Karakteristik Responden}

Tabel 1. Distribusi Frekuensi Responden Menurut Jenis Kelamin

\begin{tabular}{ccc}
\hline $\begin{array}{c}\text { Jenis } \\
\text { Kelamin }\end{array}$ & $\mathbf{n}$ & $\mathbf{\%}$ \\
\hline Laki-Laki & 16 & 30,2 \\
Perempuan & 37 & 69,8 \\
\hline Total & 53 & 100 \\
\hline
\end{tabular}

\section{Sumber : Data Primer 2019}

Responden dalam penelitian ini merupakan pasien yang telah di diagnosis gastritis dan masuk di UGD RSU GMIM Bethesda Tomohon. Dengan karakteristik jenis kelamin, perempuan dengan jumlah terbanyak $69,8 \%$ dari total 53 responden. Hasil penelitian tentang hubungan jenis kelamin dengan kejadian gastritis yang dilakukan oleh (Rondonuwu dkk. 2013) didapatkan bahwa perempuan lebih beresiko mengalami gastritis. Hal ini disebabkan oleh faktor pola makan atau diet yang tidak teratur, dan juga disebabkan perempuan lebih emosional dengan laki laki. Sehingga ketika menghadapi suatu masalah beban pikiran akan mengakibatkan timbulnya stress dan akan menyebabkan produksi asam lambung meningkat. 
Tabel 2. Distribusi Frekuensi Responden Menurut usia

\begin{tabular}{ccc}
\hline Usia & $\mathbf{n}$ & $\boldsymbol{\%}$ \\
\hline 0-17 Tahun & 9 & 17 \\
18-65 Tahun & 35 & 66 \\
66-79 Tahun & 7 & 13,2 \\
80-99 Tahun & 2 & 3,8 \\
\hline Total & 53 & 100
\end{tabular}

Sumber : Data Primer 2019

Karakteristik usia, $18-65$ tahun sebanyak $66 \%$ dari total responden. Karakteristik usia yang didapati dalam penelitian ini bervariasi, mulai dari $0-17$ tahun berjumlah 9 pasien (17\%), $66-79$ tahun sebanyak 7 pasien $(13,2 \%)$ dan $80-$ 99 tahun berjumlah 2 pasien $(3,8 \%)$. Karakteristik yang diambil berdasarkan pengukuran usia oleh WHO yaitu $0-17$ adalah usia anak - anak ke remaja, 18 - 65 yaitu remaja ke dewasa, 66 - 79 yaitu dewasa ke lansia, dan 80 - 99 yaitu lansia berusia panjang.

\section{B. Analisis Univariat}

Tabel 3. Distribusi Frekuensi Responden berdasarkan Penatalaksanaan Awal Gastritis

\begin{tabular}{ccc}
\hline $\begin{array}{c}\text { Penatalaksanaan } \\
\text { Awal Gastritis }\end{array}$ & n & \% \\
\hline Baik & 39 & 73,6 \\
Cukup & 13 & 24,5 \\
Kurang & 1 & 1,9 \\
\hline Total & 53 & 100 \\
\hline
\end{tabular}

Sumber : Data Primer 2019

Hasil dari penelitian ini menunjukan bahwa penatalaksanaan awal gastritis yang didapatkan oleh pasien pada saat masuk di UGD menunjukan bahwa 73,6\% responden mendapatkan penatalaksanaan yang baik, penatalaksanaan yang cukup berjumlah 24,5\%, dan yang mendapatkan penatalaksanaan yang kurang hanya berjumlah $1,9 \%$ dari total responden. Hal ini sejalan dengan misi rumah sakit yang menyelenggarakan pelayanan medis dasar dan spesialistik yang komperehensif dan terstandart. Menurut peneliti berdasarkan hasil penelitian, penatalaksanaan yang sering diberikan berupa pelayanan yang sigap dan cepat dalam awal penatalaksaannya, terdapat juga pemeriksaan terhadap keluhan pasien yang menjadi acuan untuk memberikan pentalaksanaan yang komperehensif. hal ini sesuai dengan standar yang baku dalam pelayanan gawat darurat dan dapat menjadi acuan bagi daerah dalam mengembangkan pelayanan gawat darurat khususnya di Unit Gawat Darurat (UGD). Hal ini sejalan dengan prinsip umum pelayanan Unit Gawat Darurat (UGD) di Rumah Sakit menurut Kemenkes RI Nomor 856 Tahun 2009, yaitu setiap rumah sakit wajib memiliki pelayanan gawat darurat yang memiliki kemampuan: melakukan pemeriksaan awal kasus-kasus gawat darurat dan melakukan resusitasi dan stabilisasi (life saving).

Tabel 4. Distribusi Frekuensi Responden berdasarkan skala nyeri

\begin{tabular}{ccc}
\hline Skala & n & \% \\
Nyeri & & \\
\hline Ringan & 41 & 77,4 \\
Sedang & 9 & 17 \\
Berat & 3 & 5,7 \\
Total & 53 & 100
\end{tabular}

Sumber : Data Primer 2019

Pengukuran skala intensitas nyeri alat yang digunakan adalah number rating scale (NRS) dimana instrumen tersebut merupakan metode pengkajian skala nyeri pada pasien yang telah baku dan menjadi patokan dalam mengkaji skala nyeri pasien. Hasil dari pengukuran skala nyeri terhadap responden, intensitas skala nyeri yang terbanyak adalah skala nyeri ringan sebanyak 41 responden $(77,4 \%)$ dari total responden yang ada. Hal ini didukung oleh penatalaksanaan awal yang didapati pada saat masuk di UGD. Yang dimana penatalaksanaannya dilakukan secara komperehensif sehingga dapat menekan skala intensitas nyeri yang tinggi menjadi rendah. 


\section{Analisis Bivariat}

Tabel 5. Analisis hubungan antara penatalaksanaan awal gastritis dengan skala nyeri

\begin{tabular}{|c|c|c|c|c|c|c|c|c|c|c|}
\hline \multirow{3}{*}{$\begin{array}{c}\text { Penat } \\
\text { alak } \\
\text { sanaa } \\
\text { n }\end{array}$} & \multicolumn{8}{|c|}{ Skala nyeri } & \multicolumn{2}{|c|}{ Hasil } \\
\hline & \multicolumn{2}{|c|}{ berat } & \multicolumn{2}{|c|}{$\begin{array}{c}\text { sedan } \\
\mathrm{g}\end{array}$} & \multicolumn{2}{|c|}{ ringan } & \multicolumn{2}{|c|}{ total } & $\mathrm{P}$ & $r$ \\
\hline & $\mathrm{n}$ & $\%$ & $\mathrm{n}$ & $\%$ & $\mathrm{n}$ & $\%$ & $\mathrm{n}$ & $\%$ & $\begin{array}{l}0,0 \\
66\end{array}$ & - \\
\hline $\begin{array}{c}\text { Kura } \\
\text { ng }\end{array}$ & 0 & 0 & 0 & 0 & 1 & $\begin{array}{c}2, \\
4\end{array}$ & 1 & $\begin{array}{l}1, \\
9\end{array}$ & & 55 \\
\hline Cuku & 3 & 1 & 5 & 44 & 6 & 14 & 1 & 24 & & \\
\hline $\mathrm{p}$ & & $\begin{array}{l}0 \\
0\end{array}$ & &, 4 & & 6 & 3 &, 5 & & \\
\hline baik & 0 & 0 & 5 & $\begin{array}{l}55 \\
6\end{array}$ & $\begin{array}{l}3 \\
4\end{array}$ & $\begin{array}{c}82 \\
, 9\end{array}$ & $\begin{array}{l}3 \\
9\end{array}$ & $\begin{array}{l}73 \\
6\end{array}$ & & \\
\hline Total & 3 & $\begin{array}{l}1 \\
0 \\
0\end{array}$ & 9 & $\begin{array}{c}10 \\
0\end{array}$ & $\begin{array}{l}4 \\
1\end{array}$ & $\begin{array}{c}10 \\
0\end{array}$ & $\begin{array}{l}5 \\
3\end{array}$ & $\begin{array}{c}10 \\
0\end{array}$ & & \\
\hline
\end{tabular}

Sumber : Data Primer 2019

Berdasarkan hasil penelitian dari dua variabel yaitu penatalaksanaan awal gastritis dengan skala nyeri pasien di UGD RSU GMIM Bethesda Tomohon di dapati nilai signifikan sebesar 0,066 ( $p>0,05)$, hal ini menunjukan hubungan tidak signifikan antara penatalaksanaan awal gastritis dengan skala nyeri pada pasien yang telah di diagnosis gastritis dan masuk di UGD RSU GMIM Bethesda Tomohon, dengan koefisien korelasi spearman (r) sebesar -0,255 yang menunjukan koefisien korelasi lemah dan bernilai negatif, maka kedua variabel mempunyai hibungan tidak searah, dengan demikian, dapat disimpulkan semakin tinggi penatalaksanaan awal gastritis yang didapatkan maka semakin rendah intensitas skala nyeri yang di rasakan oleh pasien gastritis RSU GMIM Bethesda Tomohon.

Hasil ini sejalan dengan penelitian oleh Tharir dan Nurlaela pada tahun 2018 dengan pembahasan pengaruh pemberian penatalaksanaan medis dengan penurunan intensistas nyeri pada pasien gastritis yang didapati sesudah dilakukan penatalaksanaan terjadi penurunan intensitas nyeri sebanyak 52\% menjadi skala nyeri sedang dan $47 \%$ menjadi skala nyeri ringan.

Hasil dari penelitian dua variabel yaitu penanganan awal gastritis dengan skala nyeri pasien menunjukan bahwa hubungan tidak signifikan dengan korelasi lemah dikarenakan terdapat beberapa faktor yang mempengaruhi dari hasil variabel tersebut seperti skala intensitas nyeri yang memiliki faktor-faktor yang mempengaruhi seperti : usia, jenis kelamin, dan pandangan dalam mengatasi nyeri dari setiap responden berbeda-beda. (Santoso, 2015) peneliti berasumsi hal ini menguatkan bahwa skala intensitas nyeri tidak hanya di pengaruhi oleh penanganan awal gastritis yang responden dapatkan. Adapun dalam hasil penelitian dapat dipengaruhi oleh kesalahan yang berasal dari pengaruh-pengaruh yang dapat diketahui dengan pasti atau ditimbulkan oleh adanya faktor tetap yang mengakibatkan hasil pengujian cenderung lebih tinggi atau lebih rendah dari nilai sebenarnya (true value).

Penyebab yang dapat mengakibatkan timbulnya kesalahan sistematika, seperti kelemahan metode pengujian, responden yang homogen, kondisi akomodasi dan lingkungan pengujian, kurang ketidakstabilan penanganan perawat, atau bahan standar yang tidak mampu telusur ke standar pengukuran nasional atau internasional. Kesalahan-kesalahan tersebut tidak mempengaruhi penyebaran data, tetapi akan menunjukkan bias rerata hasil pengujian sehingga kesalahan sistematika akan mempengaruhi akurasi suatu hasil pengujian. Bias merupakan deviasi yang terjadi secara konsisten terhadap hasil pengujian dari nilai benar yang disebabkan kesalahan sistematika.

Berdasarkan hasil penelitian (Tharir dkk. 2018) Penurunan nyeri timbul karena adanya kemampuan sistem saraf untuk mengubah berbagai stimuli mekanik, kimia, termal dan elektris menjadi potensial aksi yang di jalarkan kesistem saraf pusat. Stimuli mekanik yaitu pemberian relaksasi napas dalam hal ini dikarenakan teknik relaksasi pernapasan merupakan suatu bentuk asuhan keperawatan, yang dalam hal ini perawat mengajarkan kepada klien bagaimana cara melakukan napas dalam, napas lambat (menahan inspirasi secara 
maksimal) dan bagaimana menghembuskan napas secara perlahan dan dapat menurunkan intensitas nyeri. Perubahan respon nyeri sebelum interfensi napas dalam menunjukkan respon tingkah laku terhadap nyeri rata-rata mengaduh, meringis, gelisah dan fokus pada aktivitas menghilangkan nyeri serta respon emosional berupa menangis dan diam namun setelah di lakukan intervensi yaitu teknik relaksasi napas dalam, di dapatkan respon tingkah laku terhadap nyeri sudah berkurang begitu juga respon musular ikut berkurang. Teknik relaksasi napas dalam terlihat memberikan efek relaksasi kepada pasien hal ini terbukti bahwa selama di lakukan intervesi tidak ada pasien yang menolak ketika di beri perlakuan, klien mengalami penurunan skala nyeri antara 34 dangan skala nyeri sedang dan ringan.

\section{SIMPULAN}

Penatalaksanaan awal gastritis yang diterima pasien gastritis di UGD RSU GMIM Bethesda Tomohon lebih dari setengah memiliki kategori atau predikat baik, dengan Skala intensitas nyeri pada pasien gastritis di UGD RSU GMIM Bethesda Tomohon masuk dalam kategori skala nyeri ringan dengan kuantitas terbanyak. Dari kedua variabel memiliki hasil hubungan tidak signifikan dan bernilai negatif antara penatalaksanaan awal gastritis dengan skala nyeri pasien gastritis di UGD RSU GMIM Bethesda Tomohon, namun dapat disimpulkan semakin tinggi penatalaksanaan awal gastritis yang didapatkan maka semakin rendah intensitas skala nyeri yang di rasakan oleh pasien gastritis RSU GMIM Bethesda Tomohon.

\section{DAFTAR PUSTAKA}

Anggita, N. (2012). Hubungan faktor konsusmsi dan karakteristik individu dengan persepsi gangguan lambung pada mahasiswa penderita gangguan lambung di pusat kesehatan mahasiswa Universitas indonesia tahun 2011. Universitas Indonesia. Jakarta
Amin, M., K. (2017). Penerapan Terapi Kompres Air Hangat Untuk Mengurangi Nyeri Pada Pasien Gastritis Di Ruang Dahlia Rsud Dr. Soedirman Kebumen. STIKES Muhammadiyah Gombong. Gombong

Fatmaningrum. W., Kinasih A.,T., dkk.(2009). Hubungan Antara Kebiasaan Merokok dan Minum Kopi dengan Kejadian Gastritis di Dusun Turi, Desa Turirejo, Kecamatan Lawang, Kabupaten Malang.2009. Universitas Airlangga. Surabaya

Depkes RI (2014). Profil Kesehatan Indonesia 2014. October 15, 2018. http://www.depkes.go.id/resources/do wnload/pusdatin/profil-kesehatanindonesia/profil-kesehatan-indonesia2014.pdf.

Kemenkes RI. (2009), Keputusan Menteri Kesehatan Republik Indonesia Nomor 856/Menkes/SK/IX/2009. Oktober 16, 2018.

https://sardjito.co.id/sardjitowp/wpcontent/uploads/2015/12/kepmenkes856-thn-2009-standar-IGD.pdf

Maulidiyah, U., (2006). Hubungan Antara Stres dan Kebiasaan Makan dengan Terjadinya Kekambuhan Penyakit Gastritis. Universitas Airlangga. Surabaya

Price, Anderson, S., Wilson, \& Carty, L., M. (2006) Patofisiologi Konsep Klinis Proses-Proses Penyakit, Ed 6, Vol 1\&2. Jakarta: EGC.

Priyanta, A. (2008) endoskopi Gatrointestinal. Kalimantan : UMKT

Santoso, R., B. (2015). Stop Nyeri Sekarang. Jogjakarta: Talenta Indonesia Mandiri 
e-journal Keperawatan (e-Kep) Volume 7 Nomor 1, Mei 2019

Sudoyo, A. dkk. (2009). Buku Ajar Ilmu Penyakit Dalam, Jilid 1,2,3, Edisi Keempat. Jakarta: internal publishing

Tahrir dkk (2018). Pengaruh Kinesiotapping Terhadap Penurunan Nyeri Akibat Low Back Pain Pada Ibu Hamil Trimester Iii Di Rskdia Pertiwi Makassar. Makasar : Poltekes Makasar

Rondonuwu, A., Ariel. Wulur, Andean. Lolo W., Astuti. (2013). Kajian Penatalaksanaan Terapi Pada Pasien Gastritis Di Instalasi Rawat Inap RSUP Prof Dr. $R$.D. Kandou Manado. Manado : FMIPA Universitas Sam Ratulangi.

WHO (2016). Methods And Data Sources For Global Burden Of Disease Estimates 2000-2016. October 15, 2018.

http://www.who.int/healthinfo/global burden_disease/GlobalDALY meth od_2000_2016.pdf?ua $=1$ 